\author{
Preventive Care in Nursing \& Midwifery Journal \\ 2018; 8(3): 18-26
}

\title{
Assessing the Quality of Receiving Patients' Informed Consent in the Surgical Wards of Hospitals Affiliated to Zanjan University of Medical Sciences
}

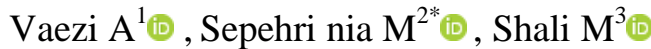 \\ ${ }^{1}$ Department of Medical-Surgical Nursing, School of Nursing and Midwifery, Zanjan University of Medical Sciences, Zanjan, Iran * \\ ${ }^{2}$ Department of pediatric Nursing, School of Nursing and Midwifery, Zanjan University of Medical Sciences, Zanjan, Iran \\ ${ }^{2} \mathrm{PhD}$. Student Nursing, Tehran University of Medical Sciences, Tehran, Iran
}

*Corresponding Author: Department of pediatric Nursing, School of Nursing and Midwifery, Zanjan University of Medical Sciences, Zanjan, Iran

Email: m.sepehrinea@zums.ac.ir

Received: 3 Sep $2019 \quad$ Accepted: 24 Dec 2019

\begin{abstract}
Background: Informed consent is the cornerstone of medical ethics and is related to four out of ten articles of the patient's legal charter, aimed at supporting the patient and clarifies ethical principles in the physicianpatient relationship.

Objectives: The purpose of this study was to assess the quality of receiving patients' informed consent in the surgical wards in Zanjan University of Medical Sciences.

Methods: In this descriptive cross-sectional study, all patients, admitted to surgical wards of public hospitals in Zanjan, were selected through stratified random sampling method. Data were collected after admission and before surgery, using a questionnaire designed according to library studies and considering Sheikh Taheri et al.'s study in two sections: general and specific. Mann-Whitney and Kruskal-Wallis tests were used to analyze the results. The content validity method was used to determine the validity, and the reliability of the questionnaire was evaluated by internal reliability using Cronbach's alpha coefficient.

Results: The number of patients was 400 (211 males and 189 females) and their mean age was 33.78. The results showed that $24 \%$ of the samples rated as "appropriate" the process of signing the consent form, and $19 \%$ of them considered the status of information submission appropriate. Three percent of the respondents regarded the comprehensibility of the questionnaire, and $12 \%$ considered the voluntary nature of obtaining the informed consent, as well as $19 \%$ found the relationship between the physician and the patient as appropriate. Other findings revealed that there was no significant relationship between sex and marital status with the sum of the questionnaire dimensions, but there was a significant relationship between the type of hospitalization and how to submit information consent and the process of signing the consent form, and also between the number of hospitalizations. Moreover, the type of job was found to be statistically significant with the form signature process variable.

Conclusion: This study found that there were some shortcomings in the process of obtaining a surgical informed consent. Therefore, considering the role of the patient in the process of obtaining informed consent, providing sufficient information on physician's treatment, training physicians and providing the patient with the opportunity to choose the treatment method can be effective in improving the quality of obtaining an informed consent.
\end{abstract}

Keywords: informed consent, patient, surgery

Introduction 
Informed consent is the cornerstone of medical ethics. In Iran, four of the ten articles of the patient's legal charter specifically address the issue of informed consent. At the age of essential change in the structure of the medication system, informed consent marks one of the cornerstones of offering information to the patient in connection with treatment and decision making [1]. The objective is supporting the patient and clarifying the moral principles of relationship between the physician and the patient [2]. The word consent should be interpreted as the patient's autonomy, indicating his/her freedom of choice to accept or reject the procedure, no matter it will end up with dangerous consequences, if any [3]. The word informed also means providing the patient with information and answering his/her questions. Since majority of the surgical procedures are complicated and whose dangers and advantages are unknown to the patient, s/he undergoing surgical operation needs to be provided with more information and guidance on the operation. Though being ordinary and simple for the physician, the surgical operation information is new and puzzling for the patient; therefore, it will be necessary to provide the patient with diagnosis and treatment information, the surgical procedure and its advantages or disadvantages as well as treatment alternatives [4].

Previous studies have suggested a relationship between getting informed consent and right clinical results-take for instance the opportunity to check symptoms of diseases and pain, promotion of the patient's mental health, his/her better performance, and ensuring the physiological standards. The practice is expected to result in the patient's more active contribution to the medication process and higher level of his/her satisfaction with the kind of treatment thus offered [5,6]. Based on the Clinical Affairs Council guidelines for designing informed consent, any information consent sheet should include easy to understand and non-technical jargons and lexicon, and the writer should be cautious not to use such statements as "The physician will be free to choose any method of treatment $\mathrm{s}$ he deems right for the patient" because court considers these types of statements very broad and non-technical. A study conducted in 2000, involving 540 patients in the US hospitals, revealed that informed consents were designed mostly to relinquish the legal responsibility of hospitals and physicians. Hence, the study concluded that the informed consents are devoid of sufficient content to meet the legal and moral standards of obtaining informed consent[7].

The informed consents obtained from patients are valid depending on its signatory. If s/he is not qualified to voice consent to the medical treatment, only eligible individuals (or the patient's legal guardian) would be right to ink the sheet. Kabirzadeh et al, surveying the records of 540 patients in Iran's northern province of Mazandaran, showed that about $74 \%$ of the informed consents lacked any validity. For instance, in majority of cases the hospital officials had asked the person close to the patient, who was in right sense, conscious and in good physical position at the time of the informed consent signing, to ink the sheet [8]. Sheikh Taheri et al. (2007) scrutinized the ways informed consent was received in the educational hospitals in the city of Kashan in Iranian province of Isfahan. The study findings suggested that signatories of the informed consent, including the patients signing the sheets, who were more literate, were more satisfied with the ways related informed were provided in the specialized hospitals. The study proposed taking necessary measures to provide the less literature patients, including those in general hospitals, with more information. While pointing to dissatisfaction of 41 percent of the patients with the surgical operation that at times resulted in adverse consequences, the study showed that 88.7 percent of the group of patients undergoing the research believed that the physical or surgeon should have explained the adverse consequences and possibility of death as a result of the operation. It said 66.3 percent of the patients the informed should have been provided to the patient herself/himself [9]. For the time being in Iran the signatories are required to sign the informed consent sheet only. This deprives the signatory of any opportunity to be provided with specific information concerning the surgical operation, leaving the patient with limited chance to study the form. The form is provided by (not well trained) staff of the hospital's reception department while the reception procedure is underway[8]. 
The informed consent forms' structural content is diversified with regards to the hospital it is provided. Since certain medication centers and hospitals provide an informed consent form, which bears the kind of statements which relinquish the physician and hospital staff from any legal responsibility towards outcomes of surgical operations and regarding study of a corpus of documents available in data bases, it seems that there are rare studies on receipt of informed consent in Iran. Only Amini et al. conducted a study to that effect in Tehran pertaining to a BSci thesis. Since the study's sample size was small, it has limited power of generalization [10]. Regarding the fact that only the wise and valid informed consent, obtained from patients based on the ethical and legal standards, will serve as the basis of medical ethics and since patient's share in the decisions made in connection with his/her treatment is proved to be influential in expediting the medication process and also since researches have over recent years been witnessing failures to observe standards and patients' rights code, this research is done to explore perceptions of patients on the way informed consent prior to surgical operation is received in Zanjan. It is hoped that this research will open a horizon to qualitative improvement of informed consent sheets and qualitative presurgical operation informed consent receipt in Iranian hospitals.

\section{Methods}

This study has the endorsement (A-11-764-1) of Zanjan University of Medical Sciences Research Ethics Committee as the researcher tried his/her best the data collection process will not cause any discrepancy in the patients' treatment. This study is cross-sectional in nature, conducted in the general surgery, men and women orthopedic surgery, neurosurgery, urology, eye and ear surgery wards of educational hospitals, affiliated to Zanjan University of Medical Sciences. 400 patients, or their envoys, admitted to Zanjan educational hospitals (except psychiatric hospital) in 2017 to undergo surgical operation and were assigned an appointment with the physician, underwent this study. The number of patients decided to be involved in this survey was in proportion to the extent of the hospitals they were hospitalized. The samples were selected on stratified random sampling method when they were admitted to the hospital in different times (morning and evening) of the week based on the timetable the patients were admitted to the surgical operation ward in each of the hospitals under investigation. The sample selection process was this way: The sample size required for this study was decided initially and then the patients undergoing operation in each ward a day were taken into consideration for the purpose of sampling. Then samples were drawn from the population of patients in the surgical center. (The patient samples were taken in proportion to those referring to the center to undergo surgical operation). The next phase of this survey marked interviews for several days with all the patients at the time of discharge. The informed consent signatories, who were parents or legal guardians of the patients falling under the 18 years of age and thus not yet qualified to fill up and sign the informed consent sheet, and of those not being in psychologically good mood, being mentally retarded and devoid of any sense, were asked to fill up the questionnaire. The consenting persons were excluded from the survey if were absent. The instrument for collection of data was questionnaire, designed based on library studies and with respect to the study of Sheikh Taheri et al [1] and Amini et al. [11]. It fell into two parts: General and specialized. The general part sought demographic and background information of the patients like age, sex, number of hospitalization, marital status, job, education status and the quality of hospitalization, while the specialized part included 40 questions presented in five sections. Six questions asked about the informed consent signing process, 14 about the degree of information sharing with the patient, three asked about the degree of the informed consent form's understandability and six items asked about physician's communication with the patient. To ensure validity of the questionnaire, the researcher used methods for assessment of content validity: Two surgeons, two ethics specialists, two patients and four members of the board of instructors in the field were asked to express opinion on the content of the questionnaire. Cronbach's alpha coefficient was used to check the internal reliability of the questionnaire. To ensure internal reliability of the questionnaire, it was distributed among twenty patients before the 
main phase of the study and after data collection, the data were analyzed through SPSS software. The data thus obtained showed that Cronbach's alpha coefficient was at the level of 0.85 . The figure suggested that the questionnaire was both reliable and valid. The questions were developed based on the Likert scale and after scoring, the scores were divided into five categories: highly inappropriate, inappropriate, average, appropriate and very appropriate. The questionnaire was cleared of any ambiguity with respect to the answers given by the patients. Then the time for distribution of the questionnaire among the respondents was decided. The questionnaire was given to the patient or the consenting body after the patient's admission to the ward and before surgery and was returned back instantly once filled up in presence of the researcher. The questions of the questionnaire were explained well to the respondent on demand. The responses were rated as "Very Inappropriate" with a score of zero, "Inappropriate" with a score of 1 , and "Medium" with a score of 2. It also received a "good" score of 3 and a "very good" score of 4 . The questionnaires filled up by the respondents were interpreted by the SPSS software version 19. The mean value, the $95 \%$ confidence interval and standard deviation of scores for all five dimensions of the informed consent were estimated. An acceptable score of four was set for each question. Thus, the total number of questions related to submitted information was 56 points, comprehensibility of 12 points form, 24 points voluntary, 44 points interaction and communication and the process of signing consent form was 24 points. Average scores falling below $25 \%$ were rated as poor, those within the range of $25 \%$ to $50 \%$ were considered as moderate, those within the range of 50 to $75 \%$ were taken as good, and those within the range of $75 \%$ or more were regarded as excellent. The questionnaires filled up by the group were analyzed using such descriptive statistics indices as frequency distribution tables, charts, percentages, averages, etc.; various tests were used in accordance with the levels for measurement of the (nominal, sequential, interval and relative) variables: Pearson test was used to analyze the correlation of variables; KolmogorovSmirnov test was used to check the normality of the data and the non-parametric tests of MannWhitney and Kruskal-Wallis were used for path analysis and structural equations

\section{Results}

A total of 400 people filled up the questionnaire. They fell with the age range of 20 and 72 . Their age average was 33.78. Table 1 shows other demographic information of the group.

Table 1: Demographic information of the participants

\begin{tabular}{|l|c|c|c|}
\hline \multirow{2}{*}{ Sex } & Background Features & Number & Frequency \\
\hline \multirow{4}{*}{ Marital Status } & Male & 211 & $53 \%$ \\
\hline \multirow{4}{*}{ Education } & Female & 189 & $47 \%$ \\
\cline { 2 - 4 } & Married & 240 & $60 \%$ \\
\hline \multirow{3}{*}{$\begin{array}{c}\text { Sype of } \\
\text { Hospitalization }\end{array}$} & $\begin{array}{c}\text { Primary or Under } \\
\text { Diploma }\end{array}$ & 160 & $40 \%$ \\
\hline \multirow{4}{*}{$\begin{array}{c}\text { Number of } \\
\text { Hospitalization }\end{array}$} & $\begin{array}{c}\text { Diploma or Post- } \\
\text { Diploma }\end{array}$ & 156 & $39.8 \%$ \\
\cline { 2 - 4 } & Graduate or higher & 138 & $34.5 \%$ \\
\cline { 2 - 4 } & Emergency & 216 & $26.5 \%$ \\
\cline { 2 - 4 } & Ordinary & 184 & $54 \%$ \\
\cline { 2 - 4 } & $\begin{array}{c}\text { Without Precedence of } \\
\text { Hospitalization }\end{array}$ & 232 & $56 \%$ \\
\cline { 2 - 4 } & Twice & & $58 \%$ \\
\cline { 2 - 4 } & More Times & 92 & $23 \%$ \\
\hline
\end{tabular}


Table 2 illustrates information on the five dimensions of the informed consent process. Based on the data, $24 \%$ of the samples considered the procedure for signing of the informed consent as "appropriate"; moreover, 19\% considered that the way the information was offered was "appropriate"; $3 \%$ of the individuals believed that the voluntary nature of informed consent receipt was "appropriate" and 19 percent said communication between physician and patient was at the "appropriate" level. They knew. A total of 24 patients $(6 \%)$ had signed the informed consent themselves, while the forms for 336 others ( 84 percent) were signed on their behalf by the spouse; for $22(5.5 \%)$ patients, however, the forms were signed by their father or parents and for 18 patients $(4.5 \%)$ other individuals had signed the forms. Investigation of each part of the questionnaire showed that $32 \%$ of patients were embarrassed and anxious when filling up the informed consent form; $45 \%$ of patients considered that the medical explanations regarding the surgical complications were at the "moderate" level and 30\% of the respondents evaluated the explanations as "inappropriate."

satisfaction with the information provided in the normal hospitalization group was higher than that in the emergency one. According to KruskalWallis test, there was a statistically significant

relationship ( $\mathrm{p}$ value being less than 0.001) between the number of hospitalizations and the type of occupation and the form signing process. This is while the people with the precedence of hospitalization for three or more times and the staff group were more satisfied with the informed
Sixty percent of patients rated the understanding of the technical jargons of the informed consent form as "inappropriate" and $47 \%$ of the individuals believed that physician-patient contribution and cooperation in various stages of the treatment was "inappropriate." Furthermore, $30 \%$ of the patients believed that their choice of treatment was at the moderate level, while $45 \%$ took it as "inappropriate." $85 \%$ of the patients were interested to receive comprehensive information on their disease and their treatment by the physician and $15 \%$ were reluctant to receive the information. Twenty percent of the samples believed that understandability of the physician's explanations on the treatment process were at "appropriate" level and 53\% said they were at the "moderate" level. The results showed no significant relationship between sex and marital status and overall score of the questionnaire dimensions but there was a significant relationship between the type of hospitalization and the type of information and the process of signing the consent form (MannWhitney test). This means that the average

consent form signing process. There was a statistically significant relationship between the score given to comprehensibility of the questionnaire (0.006), voluntary consent process (0.002) and the relationship between the variables of the physician-patient communication and the educational level (0.005). This means that the mean of the dimensions mentioned was higher in the group holding the bachelor's and higher educational degrees

\begin{tabular}{|l|c|c|l|c|c|c|c|}
\cline { 2 - 8 } \multicolumn{1}{l|}{} & \multicolumn{5}{|c|}{ Type of Answer } & Highly \\
Questionnaire & $\begin{array}{l}\text { Very } \\
\text { Appropriate }\end{array}$ & Appropriate & $\begin{array}{l}\text { Neither } \\
\text { Inappropriate } \\
\text { Nor } \\
\text { Appropriate }\end{array}$ & Inappropriate & $\begin{array}{l}\text { Average } \\
\text { Variance }\end{array}$ \\
\hline $\begin{array}{l}\text { Informed } \\
\text { Consent } \\
\text { Signature Process }\end{array}$ & 25 & 72 & 153 & 15 & 35 & 2.69 & 1.58 \\
\hline $\begin{array}{l}\text { Information } \\
\text { Submission }\end{array}$ & 18 & 61 & 143 & 96 & 82 & 2.32 & 1.63 \\
\hline $\begin{array}{l}\text { Level of } \\
\text { Understandability } \\
\text { of the Informed }\end{array}$ & 1 & 11 & 76 & 143 & 169 & 1.88 & 1.97 \\
\hline
\end{tabular}




\begin{tabular}{|l|c|c|c|c|c|c|c|}
\hline Consent Form & & & & & & \\
\hline $\begin{array}{l}\text { The Degree of } \\
\text { Voluntariness of } \\
\text { the Process for } \\
\text { Receipt of }\end{array}$ & 1 & 50 & 104 & 125 & 120 & 2.15 & 2.34 \\
$\begin{array}{l}\text { Informed } \\
\text { Consent }\end{array}$ & 29 & 49 & 106 & 135 & 86 & 2.43 & 2.41 \\
\hline $\begin{array}{l}\text { Physician-Patient } \\
\text { Communication } \\
\text { Level }\end{array}$ & 29 & & & & & & \\
\hline
\end{tabular}

Table 2: Frequency Distribution of Responses Given to Questionnaire in Proportion to Dimensions of the Questionnaire

\section{Discussion}

The present study aimed to investigate the effects of CBC based on film therapy on the marital satisfaction of women with low sex drive. Evaluation of marital satisfaction at the postintervention stage and its comparison with the pre-intervention phase indicated no significant difference before the intervention, while in the post-intervention phase, a significant difference was observed in this regard. Therefore, it could be concluded that the participants in the intervention group had higher marital satisfaction after the therapy sessions. Furthermore, improvements were observed in the couple's positive thinking, personal behaviors, relational and social behaviors, problem-solving, finances, economic activity, religious inclinations and behaviors, parenting, free time, and emotional relationship. This finding is consistent with the previous findings denoting the effectiveness of $\mathrm{CBC}$ in the enhancement of marital satisfaction and sexual function in married couples [26,27].

According to the current research, the women had higher satisfaction with their marital life after the intervention, which could be attributed to the tasks performed during the intervention since the participants noted and expressed their emotions during the therapy sessions. In this regard, Shafaturk et al. (2017) [28] and Asalian (2017) [29] reported that writing emotions resulted in awareness and insights toward suppressed emotions. Attending the group sessions, sharing experiences, and listening to the emotions of others helped the participants to access their emotions and express them in the group, as well as in their family. However, the results obtained by Hummel_et al. (2017) regarding CBC based on internet therapy after 24 weeks indicated that women experienced lower stress levels in their sexual functions, while no significant differences were observed in their sexual satisfaction, orgasm, and frequency of sex in the intervention group compared to the control group [30]. This discrepancy could be due to the differences in the research instruments and diagnostic methods for the malignancies associated with the samples. On the other hand, the treatment course was conducted in a virtual manner, which could be 
another reason for the diminished effect of the therapy sessions.

Within the past decade, cognitive-behavioral couple therapy has been considered to be a powerful and effective approach to addressing marital life problems [31]. In addition, this method has been reported to be an effective treatment to alleviate sexual dysfunctions in the general population when provided in a face-toface setting. Several studies have investigated the effectiveness of CBC targeting sexual function [28]. The cognitive-behavioral approach considers marital problems a result of the ineffective skills of couples, inability to solve conflicts and problems effectively, irrational expectations and beliefs, and negative behavioral exchanges [32].

The main goals of CBC in couple therapy include increasing the reinforcing agents and positive exchanges, communication skills training, and modification of thought patterns and methods of conflict resolution. Cognitive processes are the foundation of cognitive-behavioral methods for the treatment of relationship malfunctions and could effectively enhance intimacy and low sex drive [26]. Furthermore, the findings in this regard have indicated that cognitive therapy increases the marital satisfaction of married couples, especially if implemented in the form of group therapy [33]. However, evidence is scarce in the case of film therapy, and the mechanism of the efficacy of this method in counseling requires further investigation, particularly in the individuals with complicated marital relationships where it is challenging to disclose sexual function. In such cases, film therapy may be less resistant since the couples could spend a considerable time disclosing or processing in a less formal manner regarding the film contents until they finally comprehend their issues. In general, film therapy affords clients the opportunity to recount their life stories to therapists. This is a potentially valuable means for clients to arrive at insights, organize emotional experiences, and recognize their personal values. Since films encourage clients to tell their stories, they will relate to narrative therapy movements as outlined by authors such as Payne (2000) and McLeod (1997) [34].

According to the results of the present study, CBC based on film therapy was effective in the enhancement of marital satisfaction in the women with low sex drive. However, no other research was found in the literature based on film therapy interventions in case of marital conflict, and data is scarce regarding the effectiveness of $\mathrm{CBC}$ based on film therapy, specifically in the field of marital relations. Considering the high prevalence of low sex drive, there is the need for easy, costeffective, and short-term, accessible treatments, such as film therapy.

This trial had several limitations. Firstly, few women were willing to participate in the therapy session and express their sexual problems in a group. As such, we anticipated that the indirect effect of films and group discussion process will be more attractive to the participants. Another limitation was that power analysis was not calculated, and the study had a small sample size. In addition, marital satisfaction and sexual desires are complicated issues, and implementing fundamental treatments in this regard would be time-consuming. The current research was focused on women without their spouses, which is another limitation of the study. Also, we enrolled the women based on their self-reports about their physical and hormonal problems, and no laboratory testing facilities were available. Another limitation was the extend age range of the participants since sex drive largely depends on age.

Some of the main strengths of this trial were the randomized trial design, comparison of the intervention group with a waiting-list control group, considering several inclusion and exclusion criteria to reduce bias in selecting the subjects, and adopting an easy, cost-effective counseling approach.

According to the results, $\mathrm{CBC}$ based on film therapy is an effective approach to addressing low sex drive, which leads to no complications and is cost-effective

\section{Acknowledgments}

This article was extracted from an MSc thesis conducted by the corresponding author and submitted to the Department of Nursing at Arak University of Medical Sciences, Iran.

Conflict of interest: None declared.

\section{Funding:}


This study was financially supported by the Research Committee of Arak University of Medical Sciences.

\section{References}

1. Aliakbari DM. Relationship between women sexual function and marital adjustment. 2010; 4(3): 199-206.

2. Raisi M, Jafarbegloo E, Khoramirad A, Noroozi M. Association of body mass index with sexual dysfunction in women referred to health centers of Qom city, 2010, Iran. Qom Univ Med Sci J 2013, 7(5): 53-59. [In Persian]

3. Nezhad MZ, Goodarzi AM. Sexuality, intimacy, and marital satisfaction in Iranian firsttime parents. J Sex Marital Ther. 2011; 37(2): 7788.

4. Masoumi SZ, Kazemi F, Nejati B, Parsa P, Karami M. Effect of Sexual Counseling on Marital Satisfaction of Pregnant Women Referring to Health Centers in Malayer (Iran): An educational randomized experimental study. Electron physician. 2017; 9(1): 3598.

5. Althof SE, Needle RB. Psychological and interpersonal dimensions of sexual function and dysfunction in women: An update. Arab J Urol. 2013; 11(3): 299-304.

6. Barati M, Salehi O, Samavati A, Moeini B. Assessment of communication skills level among medical college students: verbal, listening, and feedback skills. J Urmia Nurs Midwifery Fac. 2012; 10(2): 145-54. [In Persian]

7. Moeini B, Karimi-Shahanjarini A, Soltanian AR, Valipour Matlabi Z. The effect of communication skills training on females referred to health centers in Bahar; applying the social support theory for increasing marital satisfaction among couples. J Educ Community Health. 2016;3(3):9-16.

8. Tadayon M, Rezaei Kheirabadi A, Molaeinezhad M, Shiralinia K. Efficacy of Cognitive Behavioral Therapy on Catastrophic thoughts on Women with primary Vaginismus: A Single-Case trial. Iranian J Obstetrics, Gynecology and Infertility. 2017;19(39):25-34. [In Persian]

9. Shakerian A, Nazari A-M, Masoomi M, Ebrahimi P, Danai S. Inspecting the Relationship between Sexual Satisfaction and Marital Problems of Divorce-asking Women in Sanandaj City
Family Courts. Procedia Soc Behav Sci. 2014; 114: 327-33.

10. Zaheri F, Dolatian M, Shariati M, Simbar M, Ebadi A, Azghadi SBH. Effective Factors in Marital Satisfaction in Perspective of Iranian Women and Men: A systematic review. Electron physician. 2016; 8(12): 3369- 77.

11. Zarnaghash M, Zarnaghash M, Shahni R. The influence of family therapy on marital conflicts. Procedia Soc Behav Sci. 2013; 84(9): 1838-44.

12. Kavitha C, Rangan U, Nirmalan PK. Quality of life and marital adjustment after cognitive behavioural therapy and behavioural marital therapy in couples with anxiety disorders. J Clin Diagn Re. 2014; 8(8): WC01- WC04.

13. Navidian A, Saadat S, Bahari F. The impact of movie therapy on vulnerable women's self-esteem referring to non-governmental social service clinics of Tehran. J Kermanshah Univ Med Sci. 2015;18(10):569-78.

14. Lavner JA, Karney BR, Bradbury TN. Does couples' communication predict marital satisfaction, or does marital satisfaction predict communication? J Marriage Fam. 2016; 78(3): 680-94.

15. Omidi A, Ahmadvand A, Najarzadegan MR, Mehrzad F. Comparing the effects of treatment with sildenafil and cognitive-behavioral therapy on treatment of sexual dysfunction in women: a randomized controlled clinical trial. Electron physician. 2016; 8(5): 2315- 24.

16. Warnock-Parkes E, Wild J, Stott R, Grey N, Ehlers A, Clark DM. Seeing is believing: Using video feedback in cognitive therapy for social anxiety disorder. Cogn Behav Pract. 2017; 24(2): 245-55.

17. Franco GE. Videogames and therapy: a narrative review of recent publication and application to treatment. Front psychol. 2016; 7: 1085.

18. Hernandez MY, Mejia Y, Mayer D, Lopez SR. Using a narrative film to increase knowledge and interpersonal communication about psychosis among Latinos. J Health Commun. 2016; 21(12): 1236-43.

19. Sánchez-Fuentes MdM, Santos-Iglesias P, Sierra JC. A systematic review of sexual satisfaction. Int J Clin Health Psychol. 2014; 14(1): 67-75.

20. Abbasi A, Jalilpour N, Kamkar A, Zadehbaghri G, Mohamed F. The Effects of Life 
Skills Training on Marital Satisfaction of Married Women: A Case Study in Dogonbadan, Iran. Armaghane danesh. 2012; 16(6): 587-94.

21. Krishna K, Avasthi A, Grover S. Validation of sexual functioning questionnaire in Indian patients. Indian J Psychol Med. 2014; 36(4):.404407.

22. Parsa A, Afrouz G, Lavasani MG, Jashni Motlagh A. Relationship between marital Satisfaction of Pregnant Women and Infant Birth weight. MEJDS. 2017; 7: 88.

23. McGahuey CA, Gelenberg AJ, Laukes CA, et al. The Arizona sexual experience scale (ASEX): reliability and validity. J Sex Marital Ther. 2000; 26(1): 25-40.

24. Bayrami R, Sattarzade N, Ranjbar koocheksarai F ,Pezeshki Mz. Male Sexual Behavior and its Relevant Factors during the Partner's Pregnancy. J Ardabil Univ Med Sci. 2008. 2008;8(4):356-63. [In Persian]

25. Hosseini F-a, Khodabakhshi-koolaee A, Taghvaee D. Effectiveness of group film therapy on happiness and quality of life among elderly adults of Kahrizak nursing home. J. Health Lit. 2016; 1(2): 109-17. [In Persian]

26. Babakhani N, Taravati M, Masoumi Z, Garousian M, Faradmal J, Shayan A. The effect of cognitive-behavioral consultation on sexual function among women: a randomized clinical trial. J Caring Sci. 2018 Jun 1;7(2):83-88

27. Shayan A, Taravati M, Garousian M, Babakhani N, Faradmal J, Masoumi SZ. The effect of cognitive behavioral therapy on marital quality among women. Int J Fertil Steril. 2018; 12(2): 99-105.

28. Şafak Öztürk C, Arkar H. Effect of Cognitive Behavioral Therapy on Sexual Satisfaction, Marital Adjustment, and Levels of Depression and Anxiety Symptoms in Couples with Vaginismus. Turk Psikiyatri Derg. 2017; 28(3): 172-180.

29. Assalian P. Psychological and interpersonal dimensions of sexual function and dysfunction. Arab J Urol. 2013; 11(3): 217-21.

30. Hummel SB, Van Lankveld JJ, Oldenburg $\mathrm{HS}$, et al. Efficacy of internet-based cognitive behavioral therapy in improving sexual functioning of breast cancer survivors: results of a randomized controlled trial. J Clin Oncol. 2017 ; 35(12): 1328-40.

31. Schofield MJ, Mumford N, Jurkovic D, Jurkovic I, Bickerdike A. Short and long-term effectiveness of couple counselling: a study protocol. BMC Public Health. 2012; 12: 735.

32. Ammari S, Amini N, Rahmani MA. The effectiveness of cognitive-behavioral couple therapy in increasing the marital compatibility of the divorce applicant couples. Int J Human Cultur Stud. 2016; 1214-19.

33. Bélanger C, Laporte L, Sabourin S, Wright J. The effect of cognitive-behavioral group marital therapy on marital happiness and problem solving self-appraisal. Am J Fam Ther. 2015;43(2):10318.

34. Sharp C, Smith JV, Cole A. Cinematherapy: Metaphorically promoting therapeutic change. Couns Psychol Q. 2002; 15(3): 269-76. 